\title{
PENERAPAN MODEL PEMBELAJARAN TAI UNTUKMENINGKATKAN HASIL BELAJAR MATEMATIKAPESERTA DIDIKKELAS IVMIN-2KOTA PALANGKARAYA
}

\author{
${ }^{1}$ *Rita Rahmaniati, ${ }^{2}$ Jakiyah Aslamiyah, ${ }^{3}$ Lastaria \\ ' Lecturer in Elementary Teacher Education, Universitas Muhammadiyah Palangkaraya, RTA Milono St. Km. I,5, \\ Palangka Raya, Indonesia. \\ ${ }^{2}$ Students in Islamic Education, Universitas Muhammadiyah Palangkaraya, RTA Milono St. Km. I,5, Palangka Raya, \\ Indonesia \\ ${ }^{3}$ Lecturer in Islamic Education, Universitas Muhammadiyah Palangkaraya, RTA Milono St. Km. I,5, Palangka Raya, \\ Indonesia.

\section{e-mail: rahmaniatirita@gmail.com} \\ ABSTRAK \\ Penelitian ini bertujuan: (I) Untuk mendeskripsikan aktivitas belajar peserta didik selama proses \\ pembelajaran matematika dengan menggunakan model TAI kelas IV MIN 2 Kota PalangkaRaya Tahun \\ Pelajaran 2018/2019, (2) Untuk mengetahui peningkatan hasil belajar matematika dengan menggunakan model \\ pembelajaran TAI kelas IV MIN 2 Kota Palangka Raya.Jenis penelitian ini adalah penelitian tindakan kelas (PTK) \\ yang berusaha memecahkan atau menjawab permasalahan yang dihadapi. Subjek dalam penelitian ini adalah \\ seluruh peserta didik kelas IV MIN 2 Kota Palangka Raya yang berjumlah 36 orang dengan I8 laki-laki dan 18 \\ perempuan.Teknik pengumpulan data yang digunakan adalah observasi dan tes. Analisis data yang digunakan \\ yaitu analisis kualitatif dan kuantitatif.Hasil dari penelitian menunjukkan bahwa: (I). Aktivitas belajar sangat baik \\ pada proses pembelajaran Matematika dengan menggunakan model pembelajaran TAI pada peserta didik kelas \\ IV MIN 2 Kota Palangka Raya (2). Peningkatan hasil belajar Matematika setelah menggunakan model \\ pembelajaran TAI pada peserta didik kelas IV MIN 2 Kota Palangka Raya hal ini terlihat dari data hasil belajar \\ peserta didik pada siklus I peserta didik memperoleh nilai rata-rata 59 dengan persentase ketuntasan klasikal \\ $47 \%$ dan pada siklus II hasil belajar peserta didik meningkat dengan skor nilai rata-rata 91,25 dengan persentase \\ ketuntasan klasikal $91 \%$.
}

Kata kunci: Model pembelajaranTAl, HasiBelajar.

\begin{abstract}
The research aim to : (I) To know the activity of student of class IV MIN-2 Palangkaraya. (2) to know the increase in mathematics learning outcomes by using the TAI IV learning model MIN 2 Palangka Raya. This type of research is classroom action research (PTK) which attempts to solve or answer the problems faced. The subjects in this study were all IV MIN 2 students in Palangka Raya City, which amounted to 36 people with 18 men and 18 women. Data collection techniques used were observation and tests. Analysis of the data used is qualitative and quantitative analysis. The results of this study indicate that: (I). Learning activities are more active in the learning process of Mathematics by using the TAI learning model on students of class IV MIN 2 in Palangka Raya (2). Improved Mathematics learning outcomes after using the TAI learning model in class IV MIN 2 students in Palangka Raya City. This can be seen from the data on student learning outcomes in the first cycle of students getting an average score of 59 with a percentage of classical completeness $47 \%$ and in the second cycle the learning outcomes of students increased by obtaining an average score of 91.25 with a percentage of $91 \%$ classical completeness.
\end{abstract}

Keywords:TAI Model, Learning Result 


\section{PENDAHULUAN}

Pembelajaran adalah proses interaksi antara guru dan peserta didik lingkungan yang ada disekitarnya yang dalam proses tersebut terdapat upaya untuk meningkatkan kualitas diri peserta didik menjadi lebih baik dari sebelumnya; Sedangkan belajar adalah aktivitas mental atau psikis yang berlangsung dalam interaksi aktif dengan lingkungan yang menghasilkan perubahanperubahan dalam pengetahuan, keterampilan dan sikap. Tujuan pendidikan tersebut dapat tercapai apabila pendidik mampu menciptakan kodisi dan suasana belajar yang kondusif. Yaitu: suasana belajar yang baik, menyenangkan, menarik, memberi rasa aman, memberikan ruang pada peserta didik untuk berpikir aktif, kreatif, dan inovatif dalam mengeksplorasi dan mengelaborasi kemampuannya.

Matematika adalah ilmu tentang bilangan dan segala sesuatu yang berhubungan dengannya yang mencakup segala bentuk prosedur operasional yang digunakan dalam menyelesaikan masalah mengenai bilangan. Pentingnya pembelajaran matematika dipelajari oleh peserta didik karena ilmu yang dipelajari berkaitan dengan penyelesaian masalah dalam kehidupan sehari-hari. Materi pembelajaran matematika yang berkaitan dengan penyelasain masalah dalam kehidupan sehari-hari yaitu materi KPK dan FPB. Materi ini dipelajari di kelas IV Madrasah Ibtidaiyah semester I.

Hasil observasiawal pada pembelajaran Matematika di MIN 2 Palangka Rayadi kelas IV materi "KPK dan FPB" menunjukkan beberapa permasalahan terhadap proses pembelajaran: Pertama, beberapa peserta didik tampak bosan dalam mengikuti proses pembelajaran ini terlihat jelas pada saat pendidik menjelaskan peserta didik lebih asyik berbicara dengan teman sebangkunya daripada mendengar penjelasan pendidik. Kedua,kurangnya minat dan motivasi dalam pembelajaran matematika, didugapendidik dalam menyampaikan materi pembelajaran cenderung bersifat monoton dan kurangnya variasi terhadap model pembelajaran. Ketiga, kurangnya interaksi peserta didik dengan pendidik. Hal ini dapat dilihat pada interaksi peserta didik saat proses pembelajaran terutama dalam menjawab pertanyaan dan mengerjakan latihan soal yang diberikan pendidik, hanya beberapapeserta didik yang terlihat aktif dalam mengerjakan tugas. Sementara peserta didik yang lain hanya diam menunggu jawaban dari temannya.Mereka juga tampakenggan bertanya pada pendidiknya saat ada materi yang belum dimengerti. $\mathrm{Hal}$ iniberdampakpadahasil belajar peserta didik rendah,terbukti dari hasil wawacara dengan guru kelas IV proses pembelajaran tersebut ditemukan hasil belajar peserta didik dari 36 ada 10 orang peserta didik yang mampu mencapai Kriteria Ketuntasan Minimal (KKM). Sementara 26 orang peserta didik masih belum mencapai KKM yang ditentukan sekolah yaitu dengan nilai 65 pada mata pelajaran matematika.Apabila hal ini tidak segera diatasi, maka peserta didik tidak akan memiliki kemampuan yang diharapkan dalam tujuan pembelajaran dan kurang memiliki bekal untuk melanjutkan materi yang lebih tinggi.

Beberapa alternative dapatdilakukanpendidik agar proses pembelajaranmenjadilebihaktif. Salah satunyadengan menerapkan suatu model pembelajaran yang dapat meningkatkan hasil belajardan aktivitas belajar peserta didik. Salah satu yangdapat digunakan adalah dengan menggunakan penerapan model kooperatif tipe TAl (Team Assisted Individualization). Pembelajaran kooperatif adalah pembelajaran yang menggunakan model pengelompokkan atau tim kecil yang terdiri dari 4-6 orang yang mempunyai karakteristik berbeda sedangkan pembelajaran kooperatif tipe TAl adalah pembelajaran kooperatif yang pada pelaksanaanya peserta didik dibagi kedalam kelompok-kelompok kecil yang heterogen. Salah satu poin penting yang harus diperhatikan untuk membentuk kelompok heterogen di sini adalah kemampuan akademik peserta didik. Masing-masing kelompok dapat beranggotakan 4-5 orang peserta didik.

Model pembelajaran koperatif ini, peserta didik biasanya belajar menggunakan LKPD (Lembar Kerja Peserta Didik) secara berkelompok. Mereka kemudian berdiskusi untuk menemukan atau memahami konsep-konsep. Setiap anggota kelompok dapat mengerjakan satu persoalan (soal) sebagai bentuk tanggung jawab bersama. Penerapan model pembelajaran kooperatif tipe TAllebih menekankan pada penghargaan kelompok, pertanggungjawaban individu dan memperoleh kesempatan yang sama untuk berbagi hasil bagi setiap kelompok. Kelebihan kooperatif tipe TAladalah dapat meningkatkan hasil belajar peserta didik, meningkatkan motivasi belajar pada diri peserta didik, mengurangi perilaku yang mengganggu, dan program ini dapat membantu peserta didik yang lemah. Kekurangan kooperatif tipe TAI adalah dapat dibutuhkan waktu yang lama untuk membuat dan mengembangkan perangkat pembelajaran, dengan jumlah peserta didik yang besar dalam kelas, maka pendidik akan mengalami kesulitan dalam memberikan bimbingan kepada peserta didiknya. 
Pentingnya melakukan penelitian ini karena model pembelajaran TAldipandang sangat efektif, dapat meningkatkan hasil belajar dan membuat proses pembelajaran menjadi menyenangkan. Selain itu, model pembelajaran TAI dapat membuat peserta didik aktif dalam proses pembelajaran. Apabila penelitian ini tidak diteliti maka dampaknya akan berpengaruh pada hasil belajar peserta didik dan tidak akan meningkat.

\section{METODE PENELITIAN}

Penelitian ini merupakan Penelitian Tindakan Kelas (PTK) yaitu suatu studi sistematis terhadap praktik pembelajaran di kelas dengan pembelajaran yang memiliki tujuan untuk memperbaiki dan meningkatkan kualitas proses pembelajaran dan hasil belajar dengan melakukan tindakan tertentu.

Menurut Kemmis dan Mc. Taggart (Sanjaya,W: 20II) Penelitian tindakan adalah suatu bentuk self-inkuiry kolektif yang dilakukan oleh para partisipan di dalam situasi sosial untuk meningkatkan rasonalitas dan keadilan dari praktik sosial atau pendidikan yang mereka lakukan, serta mempertinggi pemahaman mereka terhadap praktik dan situasi di mana praktik itu di laksanakan. Penelitian Tindakan Kelas sebagai salah satu upaya yang dapat dilakukan pendidik untuk Berdasarkan penjelasan diatas, maka PTK dapat diartikan sebagai proses pengkajian masalah pembelajaran di dalam kelas melalui refleksi diri dalam upaya untuk memecahkan masalah tersebut dengan cara melakukan berbagai tindakan yang terencana dalam situasi nyata serta menganalisis setiap pengaruh dari perlakuan tersebut.

Kehadiran dan peran peneliti dalam penelitian ini adalah melakukan penelitian dengan berkolaborasi bersama dengan seorang pendidik kelas guna memperbaiki proses pembelajaran agar sesuai dengan tujuan yang ingin dicapai. Peneliti merupakan perencana, pengajar, pengamat, pelaksana, pengumpul data, penganalisis data dan pelapor hasil penelitian. Kehadiran peneliti di dalam penelitian secara terus menerus dalam waktu yang cukup panjang dan sangat penting artinya agar dapat menghayati apa yang sebenarnya terjadi di tempat penelitian.

Subjek dalam penelitian ini adalah peserta didik kelas IV MIN 2 Kota Palangkaraya Tahun pelajaran 2018/ 2019 yang berjumlah 36 orang yang terdiri dari 18 perempuan dan 18 orang laki-laki. Teknik penelitian dalam penelitian ini melalui tes dan observasi. Observasi dalam penelitian ini adalah observasi langsung yaitu observasi dilakukan dengan cara pengamatan secara langsung untuk mengetahui hasil, tingkah laku, aktivitas peserta meningkatkan kualiatas peran dan tanggung jawab pendidik khususnya dalam pengelolaan pembelajaran.Dari beberapa definisi para ahli tersebut, maka ciri utama dari penelitian tindakan kelas adalah adanya intervensi atau perlakuan tertentu untuk perbaikan kinerja dalam dunia nyata.

MenurutSangadjidanSopiah (2010 : III-

112)

PenelitianTindakanKelasterbagimenjaditigabagia $\mathrm{n}$ :

I. Penelitian; kegiatan mencermati suatu obyek serta menggunakan aturan metodologi tertentu untuk memperoleh data atau informasi yang bermanfaat meningkatkan mutu suatu hal yang menarik minat dan penting bagi peneliti.

2. Tindakan; suatu gerak kegiatan yang senga jadi lakukan dengan tujuan tertentu, dalam penelitian ini berbentuk rangkaian siklus kegiatan.

3. Kelas; adalah sekelompok peserta didik yang dalam waktu sama menerima pelajaran sama dari seorang guru

didik dan pendidik di dalam kelas, dan objek yang diteliti secara langsung saat pembelajaran di kelas.

Data dalam penelitian ini dianalisis secara kualitatif dan kuantitatif. Data kualitatif diperoleh dari aktivitas pendidik dan peserta didik dalam pembelajaran yang dikelola pendidik dengan penerapan model TAI. Sedangkan data kuantitatif berasal dari pretest yang dilakukan diawal pertemuan dan posttest yang dilakukan diakhir pembelajaran dengan rumus:

$$
\overline{\mathrm{X}}=\frac{\sum X}{N}
$$

Keterangan:

$\overline{\mathrm{X}}=$ Nilai rata-rata kelas

$\sum \mathrm{X}=$ Total nilai yang diperoleh peserta didik

$\mathrm{N}=$ Jumlah peserta didik

$$
T B=\frac{\sum s \geq 65}{N} \times 100 \%
$$

Keterangan:

$$
\begin{aligned}
& \sum s \quad=\text { Jumlah peserta didik yang } \\
& \text { mendapatkan nilai sama } 65 \\
& \mathrm{~N} \quad=\text { Banyak peserta didik } \\
& 100 \% \quad=\text { Bilangan tetap presentase }
\end{aligned}
$$


Rita Rahmaniati, Jakiyah Aslamiyah dan Lastaria. 2019.Penerapan Model Pembelajaran Tai Untukmeningkatkan Hasil Belajar Matematika peserta Didik kelas IV MIN-2kota Palangkaraya.

TB = Ketuntasan belajar klasikal minimal $85 \%$

\section{HASIL DAN PEMBAHASAN}

I. Aktivitas PendidikdanPesertaDidik

Hasil pengamatan terhadapaktivitas pendidik dan peserta didik dalam pembelajaran Matematika pada materi KPK dan FPB yang menggunakan model pembelajaranTeam-Assisted Individualization, pada saat pembelajaran berlangsung di catat oleh dua orang pengamat yaitu pendidik dan teman sejawat, hasil pengamatan tersebut dapat dilihat pada tabelsebagai berikut:

Tabell. Data Pengamatan Aktivitas

Pendidik dalam PembelajaranMatematika

\begin{tabular}{|c|c|c|c|}
\hline $\mathbf{N}$ & $\begin{array}{l}\text { Penga } \\
\text { mat }\end{array}$ & $\begin{array}{c}\text { SikI } \\
\text { us I }\end{array}$ & $\begin{array}{l}\text { Sikl } \\
\text { II }\end{array}$ \\
\hline I & I & 3,4 & 3,5 \\
\hline 2 & II & 3,5 & 3,5 \\
\hline \multicolumn{2}{|c|}{ Rerata } & 3,45 & 3,5 \\
\hline
\end{tabular}

Tabel 2. Data Pengamatan Aktivitas

PesertaDidikdalam

PembelajaranMatematika

\begin{tabular}{|l|c|c|l|}
\hline $\mathbf{N}$ & Penga & Sikl \\
o & mat & us I & $\begin{array}{l}\text { us } \\
\text { II }\end{array}$ \\
\hline I & I & $3, I 2$ & 3,3 I \\
\hline 2 & II & 3,37 & 3,56 \\
\hline \multicolumn{2}{|c|}{ Rerata } & 3,25 & 3,44 \\
\hline
\end{tabular}

Berdasarkan tabeldiatas, melalui pembelajaran menggunakan model Team Assisted Individualizationoleh peneliti di kelas IV-A MIN 2 Kota Palangka Raya aktivitas pendidik dan peserta didik menunjukkan perkembangan yang baik. Aktivitas pendidik padasiklus I memperolehnilai rata-rata 3,25mengalamipeningkatan rata-rata 3,44padasiklus II.
Aktivitaspesertadidikpadasiklus memperolehnilai I 3,45mengalamipeningkatan rata-rata 3,50 padasiklus II.

AktivitasPendidikdalampembelajaranme ngalamipeningkatan,

halinidimaksudkanaktivitaspendidikdala mhalmembimbingsiswa,

aktivitasmemberikankesempatanbertany adanmemberipeluangpesertadidikuntukl ebihaktifdanreaktifterhadappertanyaan yang

diberikan.Aktivitaspesertadidikjugameng alamipeningkatan, yang awalnyakurangaktif,

kurangbersemangatdankurangkompakda lamkelompokmenjadilebihaktifdengan model pembelajaranTAI. Pesertadidikjugalebihkompakbekerjasam adanmampumeningkatkankemampuanbe rkomunikasi,

mengemukakanpendapatdanmampubert anyadengantemansejawatmaupundengan guru.

\section{Hasil Belajar Peserta didik}

Pada data awal nilai rata- rata peserta didik hanya memperoleh nilai rata- rata 49,94. Nilai ini masih belummemenuhidari kriteria ketuntasan minimal yang ditentukan yaitu 65. Hasil ketuntasan belajar secara klasikal hanya memperoleh nilai sebesar $22 \%$.Selanjutnyapada siklus I nilai rata- rata peserta didik mengalami peningkatan dengan rata-rata59,00 namun masih belum mencapai kriteria kertuntasan minimal, secara klasikal pun masih belum mencapai $85 \%$, karena hasi ketuntasan belajar secara klasikal pada siklus I hanya sebesar 47\%.Pada siklus II nilai rata- rata peserta didik mengalami peningkatan sangatbaik dengan perolehan 
nilai rata- rata 91,25 dengan kriteria ketuntasan secara klasikal mencapai 91\%. Peningkatan aktivitas belajarpesertadidik dan hasil belajardiduga karena pendidik menerapkan model keaktifan peserta didik dan mereka lebih berani mengungkapkan pendapatnya dan meningkatkan rasa percaya diri peserta didik. Selain itu, meningkatkan motivasi belajar pada diri peserta didik, mengurangi perilaku yang mengganggu, dan dapat membantu peserta didik yang lemahbelajarnya.

Peningkatanhasilbelajarpesertadidikmela luipenerapan model TAldalampembelajaranmatematikadigam barkansebagaiberikut :

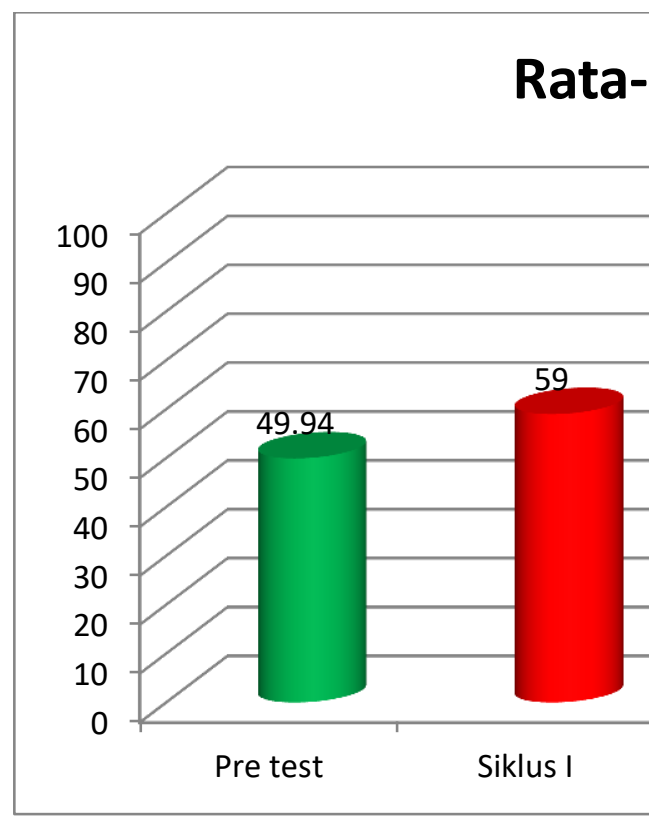

Gambar I. Diagram HasilBelajardengan Model TAl.

\author{
pembelajaranTAI.Peserta didik lebih \\ banyak mengerjakan tugas, guru lebih \\ banyak memonitor, pembelajaran lebih \\ menekankan
}

\section{Kesimpulan}

Aktivitas belajar peserta didik pada proses pembelajaran dengan menggunakan model pembelajaran Team Assisted Individualization (TAI)berkategori sangat baik.Penggunaan model pembelajaran Team Assisted Individualization dapat meningkatkan hasil belajar matematika kelas IV MIN 2 Kota Palangka Raya pada materi KPK dan FPB.

\section{DAFTAR PUSTAKA}

Aris, Shoimin.2014. 68 Model Pembelajaran Inovatif dalam kurikulum 2013, Yogyakarta: Ar-Ruzz Media.

Asep, Jihad. 20I3. Evaluasipembelajaran, Yogyakarta:Multipressindo

Eveline, Siregar.2010. Teori Belajar dan Pembelajaran, Bogor: Ghalia Indonesia.

Heri, Hermawan. 20I5. "Penerapan Pembelajaran Kooperatif Tipe TAI(Team-Assisted Individualization) Untuk Meningkatkan Hasil Belajar Siswa Kelas V SDN 4 Bajugan Pada Operasi Hitung Campuran", Jurnal Kreatif Tadulako Online, Bajugan: Universitas Tadulako

Kunandar, 2012. Langkah Mudah Penelitian Tindakan Kelas Sebagai Pengembangan Profesi Guru, Jakarta: PT RajaGrafindo Persada.

Miftahul, Huda. 20I3. Model-model PengajarandanPembelajaran, Yogyakarta :PustakaBelajar.

Muhammad Syarif Sumantri, 2016.Strategi Pembelajaran, Jakarta, PT Raja Grafindo Persada, h 40

Nurul, Ramadhani.Upaya Meningkatkan Hasil Belajar Matematika dengan Menerapkan Model Pembelajaran Kooperatif Tipe 
Think Pair Share (TPS) Pada Peserta Didik Kelas III SDN-6 Selat Hilir Kuala Kapuas Tahun Pelajaran 2014/2015.Jurnal Pendidikan Guru Dasar.(Online)Vol 2 No (ojs.umpalangkaraya.ac.id, di akses 28 Mei 2018)

Slavin Robert E. 2005. Cooperative Learning, London: Nusa Media.

Sangadji \& Sopiah. 2010. Metodologi PenelitianPendekatan Praktis dalam Penelitian. Yogyakarta: PT. C.V Andi Offset.

Ramdhani, M. T., \& Istiqlaliyah, I. (20/8). Manajemen Pembelajaran di MIS Hidayatul Insan Palangka Raya. Anterior Jurnal, I 7(2), I25-I29.

Ujiati, Cahyaningsih. 20I5. Penerapan Pembelajaran Kooperatif Tipe TAl(Team-Assisted Individualization) Untuk Meningkatkan Hasil Belajar Siswa Kelas $V$ pada materi kesebangungan dan simetri.Jurnal Cakrawala Pendas Vol.4 No I.Jurnal.Unma.ac.id diakses 20 Maret 2018).

Wina,Sanjaya. 20II. PenelitianTidakanKelas, Jakarta :KencanaPrenada Media Group 